\title{
SIMULAÇÃO VIA CFD E VERIFICAÇÃO EXPERIMENTAL DA DISPERSÃO GASOSA PARA CLASSIFICAÇÃO DE ÁREAS DE RISCO
}

\author{
C. A. NASCIMENTO ${ }^{1}$, F. J. QUEIROZ ${ }^{1}$, P. L. BARROS ${ }^{1}$, J. J. N. ALVES ${ }^{1}$. \\ ${ }^{1}$ Universidade Federal de Campina Grande \\ E-mail para contato: claudemi.alves@eq.ufcg.edu.br
}

\begin{abstract}
RESUMO - A emissão e dispersão de gases a partir de orifícios separando ambientes a diferentes pressões pode ser prevista através de modelos analíticos, empíricos ou técnicas de computação fluidodinâmica (CFD), esta última através da qual ocorre resolução de balanços de massa, quantidade de movimento e energia, descritos a partir das equações de conservação de Navier-Stokes. O objetivo neste trabalho é implementar um modelo em CFD para predição e validação, através de resultados obtidos experimentalmente, da emissão e dispersão de nitrogênio, utilizando o software ANSYS ${ }^{\circledR}$ CFX 16.1. Verificando-se após comparação, uma excelente concordância entre os resultados obtidos.
\end{abstract}

\section{INTRODUÇÃO}

A ocorrência de acidentes envolvendo incêndios e explosões motivados pela manipulação e estocagem de materiais e substâncias inflamáveis, na forma de gases, nos mais diversos setores e processos de indústrias, tais como químicas e petroquímicas, demandaram com que normas internacionais de segurança e regulamentações fossem elaboradas, no intuito de orientar acerca da prevenção e diminuição da ocorrência de tais acidentes.

No caso do Brasil, a norma que dispõe acerca disso é NBR IEC 60079-10, que corresponde a uma tradução fiel da norma internacional (SOUZA, 2016). Porém, as recomendações e definições estabelecidas nestas normas têm sido suspeitas de fornecer inadequados dimensionamentos e apresentarem caráter conservador, como relatado na literatura por diversos autores como Jordão (2002) e Weber et al. (2011). Em sentido contrário, a aplicação de Computação Fluidodinâmica (CFD) tem demonstrado ser uma solução mais realista e menos conservadora do que as normas (IVINGS et al., 2008).

Dessa forma, o presente trabalho tem por objetivo, realizar a predição e validação da emissão e dispersão de gás nitrogênio, em estado estacionário, considerando um ambiente aberto, sob diferentes condições de pressão e temperatura no reservatório, e diâmetro de secção constante, através de técnicas de Fluidodinâmica Computacional (CFD) e de dados obtidos experimentalmente. Sendo que, a escolha do gás nitrogênio, um inerte, foi motivada devido a obter uma maior segurança para realização do experimento.

\section{MATERIAIS E MÉTODOS}

Os casos retratados neste trabalho constituem-se de 5 diferentes casos de liberação, realizados tanto experimentalmente quanto simulados através do ANSYS $^{\circledR}$ CFX 16.1, sob diferentes condições de pressão e temperatura no reservatório, Tabela 1, contendo somente nitrogênio, considerando a liberação do mesmo através de um orifício de secção constante com $0,5 \mathrm{~mm}$ de diâmetro. 


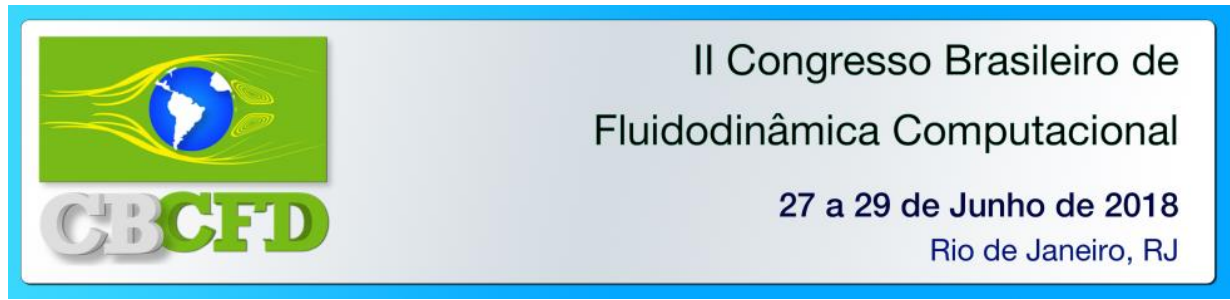

Tabela 1 - Condições de Pressão e Temperatura no Reservatório

\begin{tabular}{ccc}
\hline \multirow{2}{*}{ Case } & Pressão (Pa) & Temperatura $\left({ }^{\circ} \mathbf{C}\right)$ \\
\cline { 2 - 3 } & Reservatório & Reservatório \\
\hline $\mathbf{1}$ & $99.29 \times 10^{5}$ & 23.99 \\
$\mathbf{3}$ & $79.63 \times 10^{5}$ & 23.70 \\
$\mathbf{4}$ & $60.78 \times 10^{5}$ & 23.19 \\
$\mathbf{5}$ & $40.95 \times 10^{5}$ & 22.80 \\
& $21.16 \times 10^{5}$ & 22.62 \\
\hline
\end{tabular}

Em tratando-se da realização do experimento, nitrogênio é lançado a partir de um sistema, Figura 1, constituído de diversos pontos de monitoramento de pressão, temperatura, fluxo e concentração. Os dados referentes a pressão, temperatura e fluxo foram captados a partir de uma unidade de aquisição de dados, modelo Keysight 34972A, e os dados de concentração, foram monitorados a partir de três diferentes pontos, através de monitores de gases do modelo QRAE II.

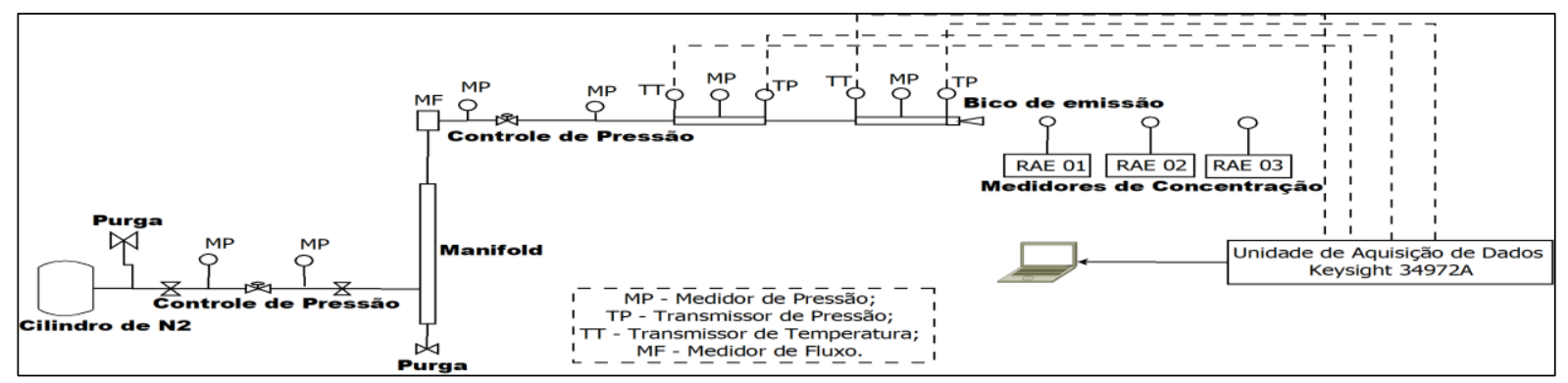

Figura 1 - Sistema de lançamento de gás

Considerando o início da etapa de aplicação de CFD, a malha numérica gerada, apresentada na Figura 2, é constituída de 4.017.965 elementos, sendo estes tetraédricos, com um maior refinamento na região de liberação do gás.

Com relação as condições de contorno inseridas no ANSYS CFX ${ }^{\circledR} 16.1$, considerou-se que o escoamento é do tipo turbulento, não-isotérmico e compressível, em regime estacionário, considerando-se o efeito da gravidade, sem perdas por atrito e o modelo de turbulência escolhido foi o SST (Shear Stress Transport). Os valores de pressão e temperatura para cada caso simulado está contido na Tabela 1, como mencionado anteriormente.

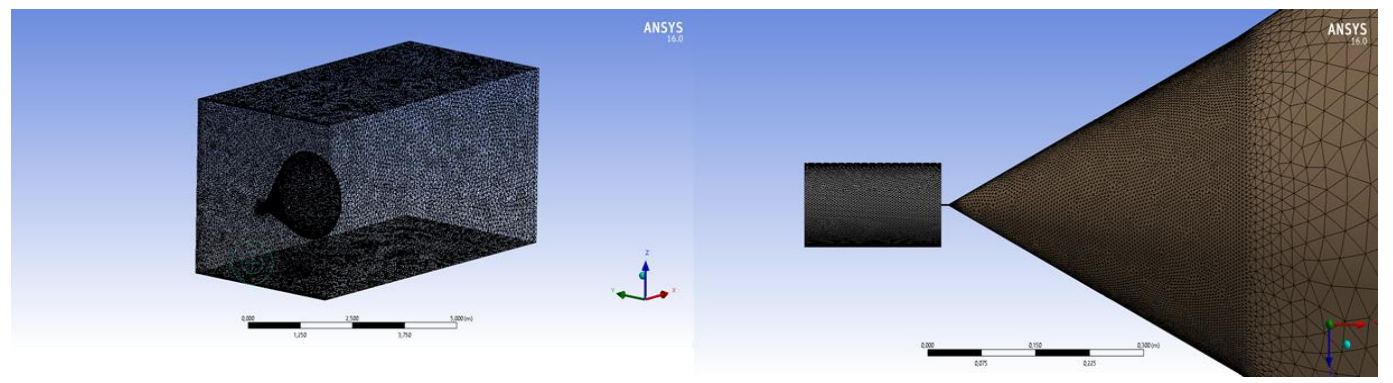

Figura 2 - Discretização da malha em 3D 


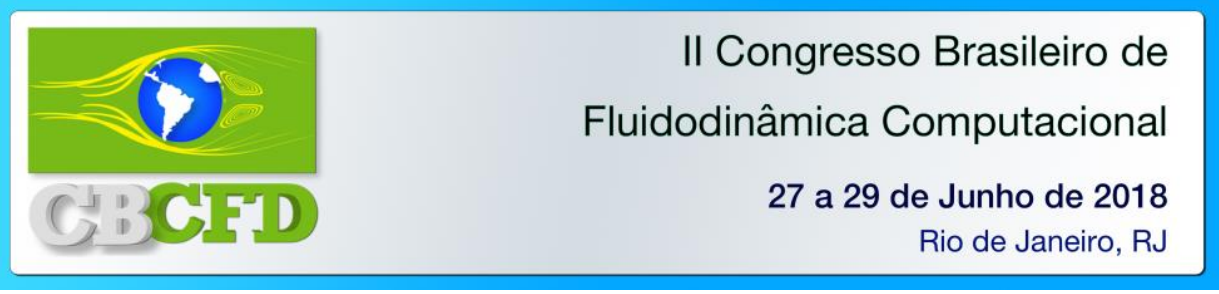

\section{RESULTADOS E DISCUSSÕES}

Comparando-se os resultados obtidos, tanto experimentalmente, quanto a partir das simulações, os seguintes gráficos, Figura 3, contendo os perfis de fração molar axial de nitrogênio com a distância, e a Tabela 2, foram obtidos. Cada gráfico representa o perfil mencionado para cada especificação de temperatura e pressão, fornecidas nos casos descritos na Tabela 1.
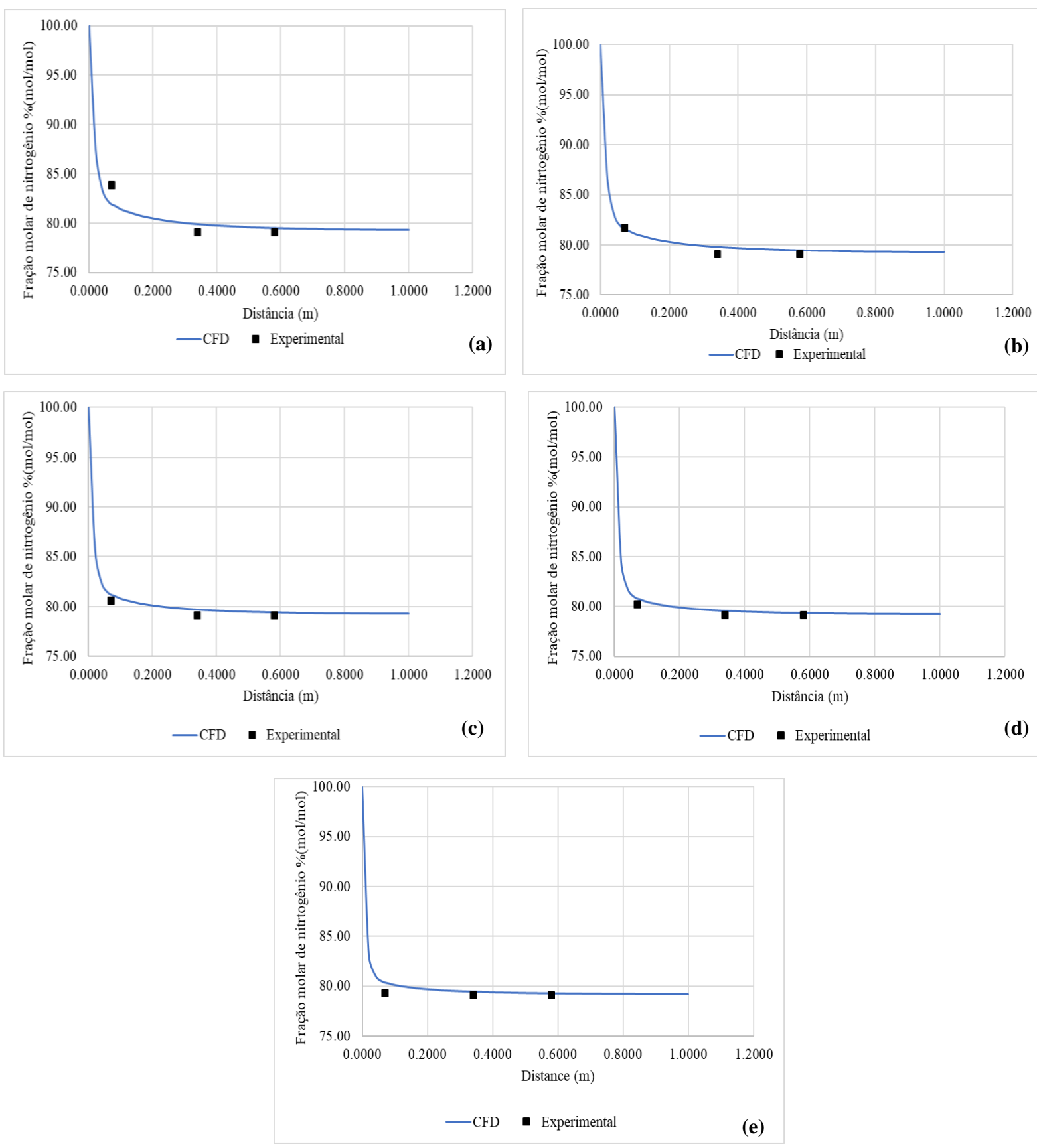

Figura 3 - Perfis de fração molar axial de nitrogênio com a distância a pressões de a) 99,29 bar; (b) 79,63 bar; (c) 60,78 bar; (d) 40,95 bar e (e) 21,16 bar no reservatório e diâmetro de orifício de 0,5 mm. 


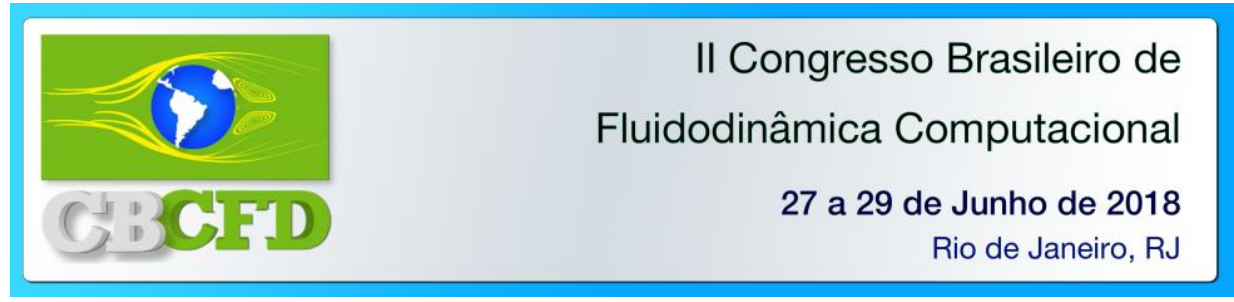

Tabela 2 - Erro médio considerando cada ponto de coleta

\begin{tabular}{llll}
\hline & Ponto 1 & Ponto 2 & Ponto 3 \\
\hline Erro Médio (\%) & & & \\
\hline & 2,51 & 0,746 & 0,380 \\
\hline
\end{tabular}

A partir dos resultados observados nos gráficos da Figura 3 e do erro médio relativo entre os resultados experimentais e os obtidos a partir das simulações no ANSYS ${ }^{\circledR}$ CFX 16.1, Tabela 2, percebe-se uma boa concordância entre os dados obtidos através de simulações numéricas via CFD e os dados experimentais. Porém, observa-se que para alguns valores na posição mais próxima ao bico, ponto 1, os valores correspondentes apresentam erros maiores. Erros estes possivelmente oriundos dos altos valores de gradiente de pressão na região mais próxima ao lançamento do gás.

\section{CONCLUSÕES}

Dessa forma, pode-se concluir que, das comparações feitas entre os resultados obtidos com CFD e com os resultados experimentais, foi possível validar os valores obtidos em CFD, demonstrando que a utilização de Fluidodinâmica Computacional para o estudo da emissão e dispersão de gases prova-se ser uma ferramenta adequada e poderosa, além de conferir maior caráter científico ao estudo de classificação de áreas de risco, possibilitando o surgimento de sugestões e possíveis modificações que venham a complementar, de forma eficaz, normas e regulamentações internacionais.

\section{REFERÊNCIAS BIBLIOGRÁFICAS}

IVINGS, M.; CLARKE, S.; GANT, S.; FLETCHER, B.; HEATHER, A. POCOCK, D.; PRITCHARD, D.; SANTON, R.; SAUNDERS, C. Area classification for secondary releases from low pressure natural gas systems. HSE, United Kingdom, 2008.

JORDÃO, D. M. Manual de Instalações Elétricas em Industrias Químicas, Petroquímicas e de Petróleo: Atmosferas Explosivas. $3^{\text {a }}$ edição, Qualitymark, Rio de Janeiro, 2002

SOUZA, A. O. Estudo e inovação de Classificação de Áreas em Atmosfera Explosiva via Fluidodinâmica Computacional. 132 p. Tese (Doutorado em Engenharia Química), Programa de Pós-Graduação em Engenharia Química, Universidade Federal de Campina Grande, Campina Grande, 2016.

WEBBER, D.M.; IVINGS, M.J.; SANTON, R.C. Ventilation theory and dispersion modelling applied to hazardous area classification. Journal of Loss Prevention in the Process Industries, Elsevier, v. 26, p. 612-621, 2011. 